\title{
Analysis of the Influence of Heat Wave on Death among the Elderly in Nanjing City
}

\author{
Xiakun Zhang1, Yanyan Zhou², Ying Tian³, Shuyu Zhang ${ }^{4 *}$ \\ ${ }^{1}$ National Meteorological Center of CMA, Beijing, China \\ ${ }^{2}$ School of Applied Meteorology, Nanjing University of Information Sciences and Technology, Nanjing, China \\ ${ }^{3}$ Inner Mongolia Meteorological Training Center, Hohhot, China \\ ${ }^{4}$ Hebei Provincial Meteorological Bureau, Shijiazhuang, China \\ Email: ^zhangsy@cma.gov.cn
}

How to cite this paper: Zhang, X.K., Zhou, Y.Y., Tian, Y. and Zhang, S.Y. (2016) Analysis of the Influence of Heat Wave on Death among the Elderly in Nanjing City. Journal of Geoscience and Environment Protection, 4, 62-71.

http://dx.doi.org/10.4236/gep.2016.411007

Received: September 26, 2016

Accepted: November 18, 2016

Published: November 21, 2016

Copyright $\odot 2016$ by authors and Scientific Research Publishing Inc. This work is licensed under the Creative Commons Attribution International License (CC BY 4.0).

http://creativecommons.org/licenses/by/4.0/

\begin{abstract}
To obtain the influence of heat waves on death in the elderly, the influence of the heat waves in Nanjing in the summers (from June to August) of 2005-2008 on death among the elderly was analyzed by using statistical methods including generalized additive models. The results showed that the death toll over these four summers in Nanjing tended to increase; on an average $10.76 \%$ more males died than females, and the mortality rate of old people aged $\geq 65$ accounted for $73.21 \%$ of all deaths. The mortality rate of older people rose with increasing maximum temperature. Furthermore, the average excess mortality rate caused by heat wave weather processes was $15.91 \%$, while it was less affected by the duration of the heat wave. The death toll of the elderly increased with the increase in humidity, dropping of atmospheric pressure, and decrease of wind speed for $1^{\circ} \mathrm{C}$ increase of maximum temperature. Under the same humidity condition, atmospheric pressure, and wind speed, the death toll during heat wave days was higher than that occurring on other days, and heat waves increased the risk of death among the elderly by $26.6 \%$ (95\% CI: $1.100-1.154)$. Daily mortality was mainly affected by the daily maximum temperature 1,4 , or 6 days later, particularly 4 days later. Heat wave was one of the principal factors, which caused the rise in death tolls in summer, and the elderly were most affected.
\end{abstract}

\section{Keywords}

Heat Wave, The Elderly, Excess Mortality Rate, Generalized Additive Models

\section{Introduction}

Climate is closely related to human health. Along with climate warming, heat wave 
events are occurring with increasing frequency [1]. A heat wave hit Europe and killed approximately 22,000 - 45,000 people in 2003 [2]. Particularly in France, the temperature had reached its highest in 50 years, and an excess death toll of approximately 14,800 in 13 cities from August 1 - 20 was attributed to the heat wave [3]. Epidemiological studies have found that some particular groups are more easily affected by heat waves due to several potential biological and environmental factors. In particular, the risk of heat stroke is higher among the elderly than in younger people, and the mortality rate dramatically increases with age [4]. By analyzing the heat wave in Memphis in the United States in 1980, it was found that all of the excess mortality occurred in people $>60$ [5]. Belmi et al. found that in the heat wave in 2003, the mortality rate of old people aged $\geq 75$ accounted for $69 \%$ of all deaths [6]. The heat wave caused the death of the elderly possibly because of the increase in body temperature due to problems with the thermoregulation function, leading to heat stroke. Patients with cardiovascular disease, including hypertension, myocardial oxygen consumption increased and kept the cardiovascular system in suspense because of restrained perspiration. Mugginess also caused vasodilatation and sticky blood, paving the way for myocardial and cerebral infarction or cerebral hemorrhage [7] [8] [9] and posed a threat to the health of the elderly. A study recently analyzed the relationship between environmental temperature and deaths caused by coronary heart disease in Beijing [10]; however, the overall influence of heat waves on deaths in the elderly in China remains to be investigated. In this paper, as an example, the influence of heat waves on death in the elderly was analyzed based on the heat waves in Nanjing in the summers of 2005-2008.

\section{Data and Methods}

\subsection{Research Area}

In recent years, the temperature of most of the cities in China has taken on ascending trend, and the Yangtze River Valley has always been prone to develop heat waves during summer [11]. Nanjing has been known as a "furnace", in which the frequency of heat waves is higher and has a significant effect on residents' health.

\subsection{Data Collection}

Mortality statistics pertaining to Nanjing from 2005-2008 provided by Jiangsu Center for Disease Control and Prevention involved ID number, name, sex, age, nationality, profession, cause of death, and the corresponding code in International Classification Diseases ICD-10.

Meteorological data in Nanjing from June to August from 2005-2008 provided by Jiangsu Climate Center involved hourly temperature, daily maximum and minimum temperatures, relative humidity, atmospheric pressure, and wind speed.

\subsection{Heat Wave}

According to the standard of climate temperature classification of the National Meteorological Center of CMA, this is used to monitor temperatures in Nanjing, a day on 
which the maximum temperature $\geq 35^{\circ} \mathrm{C}$ is classified as "a high temperature day". There is currently no unified standard for heat waves, and so in this study, heat wave was defined as a maximum daily temperature $\geq 35^{\circ} \mathrm{C}$ extending over at least three days.

\subsection{Statistical Analysis}

The sliding mean method is a method of flatness and filtering in the data processing, enabling filtration of frequently and randomly fluctuating data and the demonstration of smooth variation tendencies. In this paper, the data was processed based on the five-day sliding mean method.

The excess mortality rate is the mortality rate which exceeds a certain critical level. Initially, the heat waves of each year were identified, and next the death tolls of the elderly day by day during the heat wave were totaled, and the average death toll of the elderly on non-heat wave summer days was regarded as the reference daily average death toll. Hence according to the study by [12], the excess mortality rate of a heat wave can be defined as

$$
E M=\frac{D-D N H}{D N H},
$$

where $E M$ is the excess mortality rate detected during the heat wave; $D$ is the death toll day by day during the heat wave; and $D N H$ is the average death toll on non-heat wave summer days.

In this paper, the mortality data of the resident's day by day represented time series data characterized by lag correlation and confounding factors. A generalized additive model can reduce the lag correlation and flexibly control the confounding factors in the maximum limit of the time-series data by means of nonparametric smoothing. The daily death toll is considered a normal Poisson distribution

$$
\log [E(Y i)]=\alpha+\mathrm{S}(d o w, d f)+\mathrm{S}(a p, d f)+\mathrm{S}(r h, d f)+\mathrm{S}(w s, d f)+\mathrm{S}(\text { lagj, } d f),
$$

where $E(Y i)$ is the expected value of the death toll of the elderly during the heat wave; $\alpha$ is the intercept; $\mathrm{S}()$ is the nonparametric smoothing function; $d f$ is the freedom of motion; dow is the week dummy variable controlling the day-of-the-week effect; ap is the average pressure on the term day; $r h$ is the average relative humidity on the term day; $w s$ is the average wind speed on the term day; lagj is the daily maximum temperature before the $f^{\text {th }}$ day; and when $j=0$, it is the maximum temperature on the term day. A generalized additive model could be built by using the meteorological data and the time series of the death of the elderly during the summer from 2005-2008. Based on the control of the day-of-the-week effect, meteorological factors such as temperature, humidity, pressure, and wind speed were considered in the model.

To clarify the mortality risk of the elderly during the heat wave, the daily relative risk $(R R)$ of the death of the elderly was calculated, including $95 \%$ confidence intervals (CI); hence,

$$
R R=\mathrm{e}^{\beta+1.96 S E} \times I Q R,
$$

where $\beta$ is the regression coefficient; $S E$ is the standard deviation; and $I Q R$ is the inter- 
quartile range [13].

\section{Results}

\subsection{Evolutionary Characteristics of Population}

As saw in Table 1, the total population and the mortality rate of Nanjing increased by year. At the same time, the proportion of males was higher than that of females, and the gap between them was reduced year by year. The cohort of $0-14$ year-old was decreasing yearly, while the number of people aged 15 - 64 and $>64$ years old was increasing, which suggested a worsening of the aging problem. A proportion of a population aged $>64$ years of $7 \%$ or more are characteristic of aging societies in many countries and regions. In Nanjing, in the years of 2005-2008, this proportion amounted to $8.84 \%$, $8.91 \%, 8.98 \%$ and $9.05 \%$, respectively. Thus, Nanjing is an aging society.

\subsection{Analysis of Mortality Characteristics in Summer}

Mortality characteristics pertaining to the summers from 2005 to 2008 in Nanjing are given in Table 2. The male mortality rate was higher than that of females, and the number of fatalities among males was $10.76 \%$ higher than saw in the female population on average. The biggest gap was $11.94 \%$ in 2007 and the smallest was $10.64 \%$ in 2008 . Meanwhile, the mortality of the elderly $>64$ years old was $73.21 \%$ which was much more than the others while that of under 15 years old and 15 - 64 years old were $1.23 \%$ and $25.42 \%$, respectively. Thus, the elderly ( $\geq 65$ years old) were chosen as study objects in our research of effects of heat waves on mortality.

\subsection{Maximum Temperature and Mortality in the Elderly}

As showed in Figure 1, the variation in the mortality trend among the elderly was comparable to that of the general maximum temperature. The higher the maximum temperature was, the higher the daily mortality could be. The mortality tended to rise to a maximum as the maximum temperature also peaked. However, sometimes mortality among the elderly was seen to keep rising even when the temperature dropped dramatically after reaching its maximum, exemplified by August $13-23,2005$ and July 29-August 13, 2007. This phenomenon should be subject to further analysis.

Table 1. Analysis of population characteristics in Nanjing from 2005 to 2008 (in ten thousands).

\begin{tabular}{|c|c|c|c|c|c|c|c|c|c|c|}
\hline \multirow{2}{*}{ Year } & \multirow{2}{*}{$\begin{array}{c}\text { Total } \\
\text { population }\end{array}$} & \multicolumn{4}{|c|}{ Females } & \multicolumn{4}{|c|}{ Males } & \multirow{2}{*}{$\begin{array}{c}\text { Annual } \\
\text { mortality } \\
(\% \text { o }) \pm \text { SEM }\end{array}$} \\
\hline & & $0-14$ & $15-64$ & $\geq 65$ & Total & $0-14$ & $15-64$ & $\geq 65$ & Total & \\
\hline 2005 & 595.80 & 36.23 & 228.6 & 25.68 & 290.55 & 38.06 & 240.17 & 26.98 & 305.25 & $5.35 \pm 0.20$ \\
\hline 2006 & 607.23 & 35.26 & 235.12 & 26.45 & 296.83 & 36.88 & 245.87 & 27.66 & 310.40 & $5.15 \pm 0.22$ \\
\hline 2007 & 617.17 & 34.12 & 241.16 & 27.16 & 302.47 & 35.49 & 250.91 & 28.26 & 314.70 & $5.56 \pm 0.18$ \\
\hline 2008 & 624.46 & 32.83 & 246.43 & 27.79 & 307.08 & 33.93 & 254.70 & 28.72 & 317.38 & $5.60 \pm 0.16$ \\
\hline
\end{tabular}


Table 2. Analysis of mortality characteristics in summers from 2005 to 2008 in Nanjing.

\begin{tabular}{ccccc}
\hline & \multicolumn{3}{c}{ Year } \\
Category & 2005 & 2006 & 2007 & 2008 \\
\cline { 2 - 5 } Days & 92 & 92 & 92 & 92 \\
Death toll & 3759 & 4260 & 4213 & 4438 \\
Average daily mortality & 40.86 & 46.30 & 45.79 & 48.24 \\
The death rate of different gender: & & & & \\
Females & $45.12 \%$ & $44.15 \%$ & $44.03 \%$ & $45.18 \%$ \\
$\quad$ Males & $54.88 \%$ & $55.85 \%$ & $55.97 \%$ & $54.82 \%$ \\
The death rate of different age: & & & & \\
$\quad 14$ years old & $1.46 \%$ & $1.24 \%$ & $1.19 \%$ & $1.01 \%$ \\
15 - 64 years old & $25.22 \%$ & $25.68 \%$ & $25.89 \%$ & $24.88 \%$ \\
$\geq 65$ years old & $73.32 \%$ & $73.08 \%$ & $72.92 \%$ & $74.11 \%$ \\
\hline
\end{tabular}

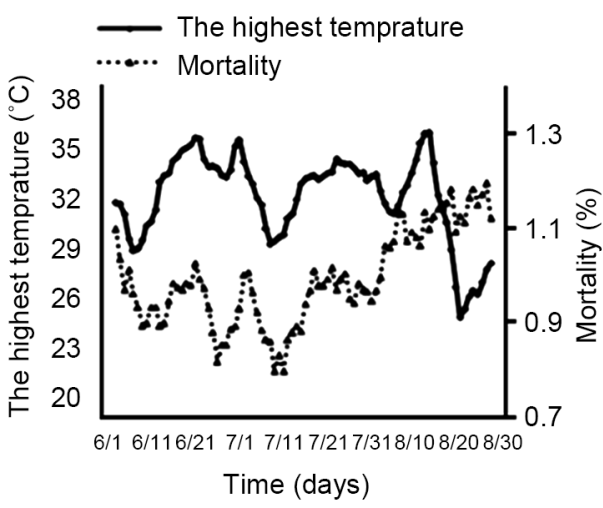

(a)

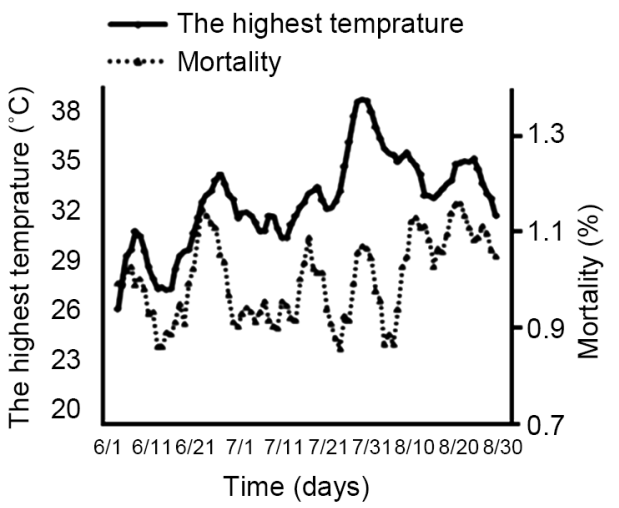

(c)

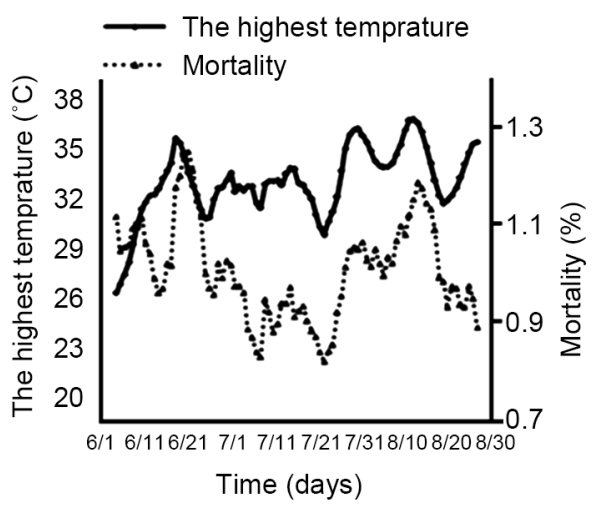

(b)

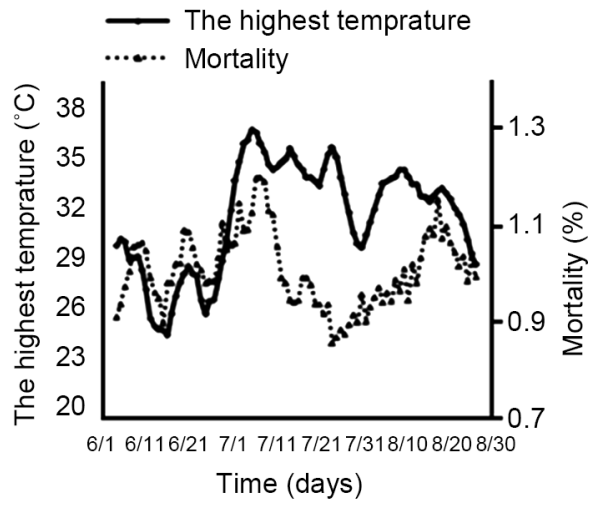

(d)

Figure 1. Diagram of daily mortality in the elderly and the maximum temperature in the summers (June, July and August) in (a) 2005, (b) 2006, (c) 2007 and (d) 2008 in Nanjing. Daily mortality = daily deaths/average deaths over the summer (June, July, and August). 


\subsection{Excess Mortality}

As showed in Table 3, according to meteorological observation records, heat waves usually lasted 3 - 4 days, but the one taking place from July 25 to August 2 in 2007 was much longer than usual with duration of nine days. The excess of mortality among the elderly during heat waves was positive, which means that heat waves could be attributed to excess mortality much more easily than non-heat waves. However, excess mortality did not increase by increasing heat wave duration. The excess mortality during heat waves with duration of four days in June 18 - 21 and August 12 - 15 in 2006 was $30.7 \%$ and $30.6 \%$ respectively, while the excess mortality during the heat wave with duration of nine days (July 25 to August 2, 2007) and a maximum temperature of $36.9^{\circ} \mathrm{C}$ was only $13.3 \%$.

\subsection{Comprehensive Analysis of the Impact of Meteorological Elements on Mortality in the Elderly}

Table 4 shows temperatures, relative humidity, and mortality in the elderly in the summers of 2005-2008 in Nanjing. As saw in the table, the standard deviations of relative humidity and deaths were larger than those of the temperature values, while the standard deviations of relative humidity and deaths on heat wave days were larger than the ones of non-heat wave days. It turned out that the undulation and changes in relative humidity and deaths on heat wave days were larger than on non-heat days. The minimum relative humidity on heat wave days was $15 \%$ and the maximum was $99 \%$, while the minimum of deaths was 19 and the maximum was 53. It was clear that with temperature and relative humidity increasing. The mortality of the elderly tended to rise, especially on heat wave days.

Pressure, wind speed, and deaths in the elderly over the summers of 2005-2008 in Nanjing are shown in Table 5. The figures indicated that the standard deviations of pressure and wind speed were small. Meanwhile, they were smaller on heat wave days

Table 3. Duration of heat waves in 2005-2008 according to meteorological observation records.

\begin{tabular}{cccc}
\hline Year & Heat waves (month/day) & Duration (days) & Maximum temperature $\left({ }^{\circ} \mathrm{C}\right)$ \\
\hline 2005 & $6 / 22-6 / 25$ & 4 & 37.1 \\
& $8 / 10-8 / 12$ & 3 & 36.6 \\
& $8 / 15-8 / 17$ & 3 & 36.9 \\
2006 & $6 / 18-6 / 21$ & 4 & 37.1 \\
$7 / 28-8 / 1$ & 5 & 36.9 \\
2007 & $8 / 12-8 / 15$ & 4 & 37.8 \\
2008 & $7 / 25-8 / 2$ & 9 & 38.2 \\
& $7 / 4-7 / 7$ & 4 & 37.3 \\
\hline
\end{tabular}


Table 4. Temperature, relative humidity, and deaths among the elderly over the summers of 2005-2008 in Nanjing.

\begin{tabular}{ccccccc}
\hline Indicator & $\begin{array}{c}\text { Standard } \\
\text { deviation }\end{array}$ & Minimum & P25 & P50 & P75 & Maximum \\
\hline Heat wave day: & & & & & & \\
Temperature $\left({ }^{\circ} \mathrm{C}\right)$ & 3.5018 & 22.9 & 28.20 & 30.70 & 34.30 & 38.1 \\
Relative humidity (\%) & 16.471 & 16 & 52.00 & 66.00 & 81.00 & 96.00 \\
Mortality & 7.478 & 19 & 30.50 & 35.00 & 40.00 & 53 \\
Non-heat wave day: & & & & & & \\
Temperature $\left({ }^{\circ} \mathrm{C}\right)$ & 3.536 & 15 & 24.60 & 26.90 & 29.50 & 34.9 \\
Relative humidity (\%) & 14.433 & 15 & 66.00 & 79.00 & 87.00 & 99 \\
Mortality & 6.544 & 17 & 28 & 32 & 37 & 48 \\
\hline
\end{tabular}

Table 5. Pressure, winds speed, and deaths in the elderly over the summers of 2005-2008 in Nanjing.

\begin{tabular}{ccccccc}
\hline Indicator & $\begin{array}{c}\text { Standard } \\
\text { deviation }\end{array}$ & Minimum & P25 & P50 & P75 & Maximum \\
\hline Heat wave day: & & & & & & \\
Pressure (hPa) & 2.7754 & 997.4 & 1002.50 & 1004.70 & 1006.90 & 1011.60 \\
Wind speed (m/s) & 1.3138 & 0 & 1.10 & 1.80 & 2.70 & 11.8 \\
Mortality & 7.478 & 53 & 40.00 & 35.00 & 30.50 & 19 \\
Non-heat wave day: & & & & & & 1014.50 \\
Pressure (hPa) & 3.4646 & 993.1 & 1002.60 & 1005.30 & 1007.60 & 11.9 \\
Wind speed (m/s) & 1.4542 & 0 & 1.40 & 2.20 & 3.30 & 17 \\
Mortality & 6.544 & 48 & 37 & 32 & 28 & \\
\hline
\end{tabular}

compared with non-heat wave days. The maximum pressure was $1011.6 \mathrm{hPa}$ and the minimum was $993.1 \mathrm{hPa}$, while the maximum and minimum wind speed was $11.8 \mathrm{~m} / \mathrm{s}$ and $0 \mathrm{~m} / \mathrm{s}$ respectively. Variations in both pressure and wind speed were small. Compared with the data on temperature and relative humidity in Table 4, the variation of pressure and wind speed could cause great changes in mortality. In other words, with a decrease in pressure and wind speed, the death toll among the elderly would increase significantly, especially on heat wave days.

The results of the generalized additive model (GAM) expressed as pressure, relative humidity, and wind speed during heat waves had great effects on mortality in the elderly as showed in Table 6. The same temperature, pressure and relative humidity could cause similar variations of elderly deaths which were bigger than wind speed. 
Every $1^{\circ} \mathrm{C}$ rise in the maximum temperature resulted in an increased mortality risk caused by pressure, relative humidity, wind speed, and the combined action of all three factors by $11.3 \%$ (95\% CI: 1.016 - 1.098), 95\% (95\% CI: 1.009 - 1.037), 7.7\% (95\% CI: 0.993 - 1.038), and $26.6 \%$ (95\% CI: 1.100 - 1.154). By analyzing results included in Table 4, Table 5, and Table 6, we could predict that with the temperature rising, the mortality risk among the elderly would increase significantly when pressure and wind speed was low and relative humidity was high.

A lag effect model, used by Ekamper [14], was employed to study the lag effects of the maximum temperature of heat waves on mortality among the elderly, and as shown in Table 7, results indicated that lags of 4 days, 1 day, and 6 days had greater influences on deaths than the others, whose regression coefficient $\beta$ were $0.3072,0.2984$, and 0.2564 , respectively. It was clear that there were lags existing in the influence of heat waves on deaths, which were from 1 - 6 days in general.

Table 6. Generalized additive model (GAM) effects of meteorological factors on deaths among the elderly according to increments of $1^{\circ} \mathrm{C}$ in the maximum temperature.

\begin{tabular}{|c|c|c|c|}
\hline Meteorological factors & $\beta$ & $\mathrm{RR}$ & $95 \% \mathrm{CI}$ \\
\hline Pressure & 0.271 & 1.113 & $1.016-1.098$ \\
\hline Relative humidity & 0.280 & 1.125 & $1.009-1.037$ \\
\hline Wind speed & 0.244 & 1.077 & $0.993-1.038$ \\
\hline Pressure + Relative humidity & 0.354 & 1.235 & $1.050-1.099$ \\
\hline Pressure + Wind speed & 0.301 & 1.153 & $0.758-0.841$ \\
\hline Relative humidity + Wind speed & 0.297 & 1.145 & $1.045-1.066$ \\
\hline Pressure + Relative humidity + Wind speed & 0.383 & 1.266 & $1.100-1.154$ \\
\hline
\end{tabular}

Table 7. Lag effect model results of the effects of maximum temperatures of heat wave days on mortality among the elderly.

\begin{tabular}{ccccc}
\hline Variables & $\beta$ & $\mathrm{SE}$ & $\mathrm{t}$ & $95 \% \mathrm{CI}$ \\
\hline Constant & 35.900 & 4.558 & 7.875 & $26.965-44.835$ \\
Maximum temperature (lag 0) & 0.094 & 0.146 & 0.645 & $0.766-0.971$ \\
Maximum temperature (lag 1) & 0.298 & 0.181 & 1.641 & $0.885-1.091$ \\
Maximum temperature (lag 2) & -0.149 & 0.182 & -0.820 & $0.713-0.831$ \\
Maximum temperature (lag 3) & 0.172 & 0.182 & 0.947 & $0.842-0.941$ \\
Maximum temperature (lag 4) & 0.307 & 0.182 & 1.684 & $1.010-1.235$ \\
Maximum temperature (lag 5) & 0.063 & 0.182 & 0.351 & $0.761-0.918$ \\
Maximum temperature (lag 6) & 0.256 & 0.146 & 1.747 & $0.083-0.993$ \\
\hline
\end{tabular}




\section{Conclusion and Discussion}

Nanjing, one of China's "three furnaces", is a city with frequent heat waves, which may be an important factor in increased mortality of residents during the summer. Elderly men appear to constitute a particularly vulnerable population with a higher risk of death during heat waves [15]. The mortality of people $>65$ years old accounted for 73.2\% of total mortality, with males having a higher mortality than females. The mortality of the elderly was between $3.9 \%$ and $30.7 \%$, while the mean mortality was $15.91 \%$ during heat waves. In the meantime, we found that the duration of heat waves had less effect on excess mortality.

The GAM was derived from a generalized linear model. It could be used for summarizing different types of functions. As a time-series datum, daily mortality is a small probability the distribution of which is generally similar to a Poisson distribution. This research built a GAM to study the effects of heat waves on mortality of elderly men considering pressure, relative humidity, wind speed, and air temperature. In the GAM, the daily mortality of the elderly in Nanjing was a dependent variable. The results showed that the death risk of the elderly increased as the temperature rose, when pressure and wind speed were low, and when the relative humidity was high. In the meantime, the results of the lag model indicated that there were lags in the effects of heat waves on mortality, and the lags could be 1 day, 4 days, and 6 days, while the most obvious one was 4 days. The lags could be caused by responding and adapting to environmental change because of the decline in organ function and interior adjustment ability of the elderly according to Xu's study [16]. Therefore, the impact of heat waves on the elderly should not be overlooked. For application of this study, hygiene departments should further strengthen public health services for the elderly, while meteorology departments should further enhance surveillance of heat waves to the benefit of the public.

The study results also had limitations. The daily mortality of the elderly was affected by many factors besides temperature, such as the change in the characteristics of populations, medical conditions, the change of healthy behavior, and other individual factors. These confounding factors were not taken into account in the model because of the lack of data. More impact factors should be subject to analysis with a view to identify the causes underlying the increased mortality among the elderly during heat waves in the future.

\section{Acknowledgements}

This work was supported by the National Natural Science Foundation of China (No. 41375121) and the Mid-term Team in the National Meteorological Center of CMA.

\section{References}

[1] IPCC (2001) Climate Change 2001: The Scientific Basis. Contribution of Working Group I to the Third Assessment Report of the Intergovernmental Panel on Climate Change. Cambridge University Press, Cambridge. 
[2] Kosatsky, T. (2005) The 2003 European Heat Waves. Eurosurveillance, 10, 148-149.

[3] Vandentorren, S., Suzan, F., Medina, S., et al. (2004) Mortality in 13 French Cities during the August 2003 Heat Wave. American Journal of Public Health, 94, 1518-1520. https:/doi.org/10.2105/AJPH.94.9.1518

[4] Patrizia, S., Giovanna, C., Manuela, D.S., et al. (2009) Susceptibility to Heat Wave-Related Mortality: A Follow-Up Study of a Cohort of Elderly in Rome. Environmental Health, 8, 50. https:/doi.org/10.1186/1476-069X-8-50

[5] Applegate, W.B., Runyan, J.W.Jr., Brasfield, L., et al. (1981) Analysis of the 1980 Heat Wave in Memphis. Journal of the American Geriatrics Society, 29, 337-342.

https:/doi.org/10.1111/j.1532-5415.1981.tb01238.x

[6] Belmi, J. (2003) The Consequences of The Heat Wave in August 2003 on the Mortality of the Elderly. La Presse Médicale, 32, 1591-1594.

[7] Zhang, S.Y. (2010) Medical Meteorological Forecast. Meteorological Press, Beijing.

[8] Li, F.R. and Li, L.P. (2008) Epidemiological Research Progress in Health Impact of Heat Wave on Urban Residents. Environmental Health, 25, 1119-1121.

[9] Cheng, X. and Su, H. (2010) Effects of Climatic Temperature Stress on Cardiovascular Diseases. European Journal of Internal Medicine, 21, 164-167.

https:/doi.org/10.1016/j.ejim.2010.03.001

[10] Tian, Z.X., Li, S.S., Zhang, J.L., et al. (2012) Ambient Temperature and Coronary Heart Disease Mortality in Beijing, China: A Time Series Study. Environmental Health, 11, 56. https:/doi.org/10.1186/1476-069X-11-56

[11] Tan, J.G. and Zheng, Y.F. (2013) Temporal and Spatial Distribution Characteristics of Heat Waves in Main Capital Cities of China. Meteorological Science and Technology, 41, 347351.

[12] Tan, J.G. (2008) Global Warming, Urban Heat Island, Heat Wave and Human Health. Nanjing University of Information Science and Technology, Nanjing.

[13] Zhang, B.L., Niu, J.P., Cao, J., et al. (2011) Time-Series Analysis of Air Pollutants and Their Health Effect on Residents in Lanzhou. Journal of Environmental Hygiene, 1, 1-6.

[14] Peter, E., van Poppel, F., van Duin, C. and Garssen, J. (2009) 150 Years of TemperatureRelated Excess Mortality in the Netherlands. Demographic Research, 21, 385-426. https:/doi.org/10.4054/DemRes.2009.21.14

[15] Fouillet, A., Rey, G., Laurent, F., et al. (2006) Excess Mortality Related to the August 2003 Heat Wave in France. International Archives of Occupational and Environmental Health, 80, 16-24. https:/doi.org/10.1007/s00420-006-0089-4

[16] Xu, X.Z., Zheng, Y.F., Yin, J.F., et al. (2011) Characteristics of High Temperature and Heat Wave in Nanjing City and Their Impacts on Human Health. Chinese Journal of Ecology, 30, 2815-2820. 
Submit or recommend next manuscript to SCIRP and we will provide best service for you:

Accepting pre-submission inquiries through Email, Facebook, LinkedIn, Twitter, etc. A wide selection of journals (inclusive of 9 subjects, more than 200 journals)

Providing 24-hour high-quality service

User-friendly online submission system

Fair and swift peer-review system

Efficient typesetting and proofreading procedure

Display of the result of downloads and visits, as well as the number of cited articles

Maximum dissemination of your research work

Submit your manuscript at: http://papersubmission.scirp.org/

Or contact gep@scirp.org 